\title{
ROMANIAN
}

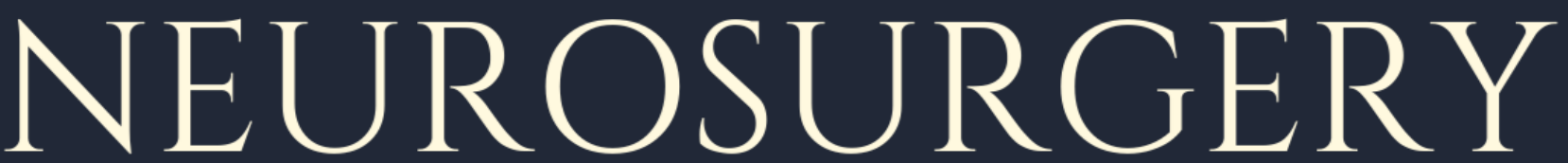

\author{
Vol. XXXIV | No. $1 \quad$ March 2020
}

\section{Computed tomography-based morphometric measurements of the atlas (C1) posterior arc}

\author{
Yasar Karatas, Bulent Kaya, \\ Mehmet Fatih Erdi, Fatih Keskin, \\ Densel Arac, Emir Kaan Izci, \\ Mehmet Uyar, Ali Sami Kıvrak, \\ Erdal Kalkan
}




\section{Computed tomography-based morphometric measurements of the atlas (C1) posterior arc}

\author{
Yasar Karatas ${ }^{1}$, Bulent Kaya ${ }^{1}$, Mehmet Fatih Erdi ${ }^{2}$, \\ Fatih Keskin², Densel Arac², Emir Kaan Izci' \\ Mehmet Uyar², Ali Sami Kıvrak ${ }^{1}$, Erdal Kalkan ${ }^{1}$ \\ 1 Medova Hospital, TURKEY \\ 2 Necmettin Erbakan University, Meram Medical Faculty, TURKEY \\ ${ }^{3}$ Meram Training and Research Hospital, Department of \\ Neurosurgery, TURKEY
}

\section{ABSTRACT}

Study design: Single-center retrospective study

Objectives: This study is performed to determine the anatomic feasibility of the C1 posterior arc screw and help select an optimal screw trajectory in treating patients with craniovertebral junction pathologies.

Material and Methods: We reported a single-centre retrospective study. Forty patients (20 male and 20 female) who underwent cervical computed tomography (CT) were chosen from the hospital records. Based on CT images, we measured left laminar length (LLL), right laminar length (RLL), left laminar angle (LLA), right laminar angle (RLA), left laminar axial thickness (LLAT), right laminar axial thickness (RLAT), left laminar coronal thickness (LLCT), right laminar coronal thickness (RLCT), and craniocaudal angle (CCA) of the C1 posterior arc.

Results: The mean values and standard deviations (SD) for nine parameters at the C1 posterior arc were determined. LLL, RLL, LLCT, and RLCT were statistically longer in men than women. RLAT was bigger in men but there was no statistical difference. RLA was statistically wider in women than men. LLA and CCA were wider in women but there was no statistical difference, LLAT was bigger in women but there was no statistical difference. There was no statistical difference in measurements by age.

Conclusion: The results of this study are important to avoid neurovascular injury and pedicle breakage because of choosing large screw while performing C1 laminar screw fixation.

\section{INTRODUCTION}

The first cervical vertebra is also referred to the atlas ${ }^{1}$. Posterior wiring ${ }^{2,3}$, transarticular screws ${ }^{4}$, and pedicle or lateral mass screws ${ }^{5}$ methods largely used for C1 posterior fixation. Recently, the screw fixation has been preferred instead of wiring or hooks because of providing rapid stability and great fusion rate ${ }^{6}$. However, screw fixation is associated with an increased risk of vertebral artery (VA), spinal cord, and root injury. Missing to identify VA anomalies can cause iatrogenic

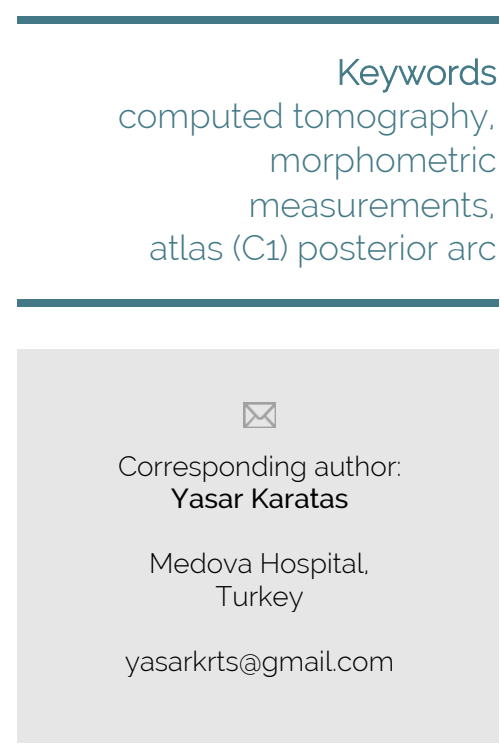

Copyright and usage. This is an Open Access article distributed under the terms of the Creative commons Attribution Non-Commercial No Derivatives License (https://creativecommons org/licenses/by-nc-nd/4.0/) which permits noncommercial re-use, distribution, and reproduction in any medium, provided the original work is unaltered and is properly cited.

The written permission of the Romanian Society of Neurosurgery must be obtained for commercial re-use or in order to create a derivative work.

ISSN online 2344-4959

(C) Romanian Society of Neurosurgery

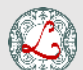

First published

London Academic Publishing www.lapub.co.uk 
VA injury and cerebrovascular accidents in cervical spine surgery ${ }^{7}$. The most dangerous level is the C1-2 level for a posterior approach and C7 for an anterior approach. Therefore, an excellent assessment for the variations in the course of the VA is vital for surgeons working from a posterior approach in the upper cervical spine ${ }^{8}$. In this study, we measured C1 posterior arc parameters to create an alternative surgical way to lateral mass screws and pedicular screws.

\section{MATERIALS AND METHOdS}

Fourty patients (20 male and 20 female) who underwent cervical computed tomography (CT) between 2017 and 2019 in our hospital were chosen from the hospital's picture archiving and communication system (PACS). None of the patients included in the study had cervical spine or craniovertebral junction trauma. Siemens Somatom Perspective 128 slices CT was used to perform CT examinations and measurements on patients. CT scans were performed by the same team. Heads of all patients were fixed in the same position on computed tomography. We assessed axial, sagittal, and coronal CT cuts and measured nine parameters on the C1 posterior arc. Left and right laminar lengths ( $L L L, R L L)$ were calculated by measuring the line from posterior tubercle to transverse foramen (Figure 1). Left and right lamina angles (LLA, RLA), which also mean mediolateral angle, were calculated as the angle of the lamina with the line passing through the anterior and posterior tubercle (Figure 2). Left and right axial laminar thicknesses (LLAT, RLAT) were measured from the middle of the lamina (Figure 3). Left and right coronal laminar thicknesses (LLCT, RLCT) were measured from the middle of the lamina (Figure 4). Craniocaudal angle (CCA) was measured as the angle of the lamina with the line that parallel to the earth (Figure 5). We investigated the difference between men and women and patients under fifty and patients over fifty years. Data were analyzed by SPSS (version 24.0, SPSS Inc.) and expressed as mean \pm SD. Comparisons were made using the t-test. Differences among the groups were assessed using the independent samples test. A p value $<0.05$ was considered statistically significant.

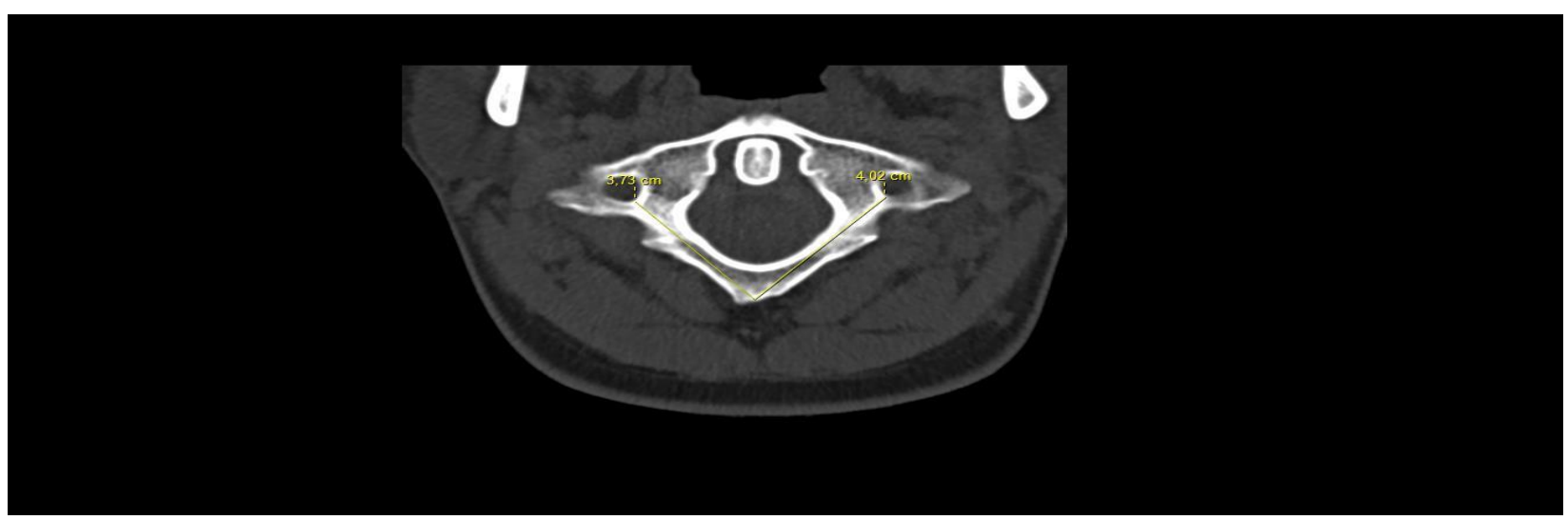

Figure 1. Laminar length was defined as linear measurement from posterior tubercle to transverse foramen both right and left side.

Figure 2. Laminar angles were defined as the angle of the lamina with the line passing through the anterior and posterior tubercle.

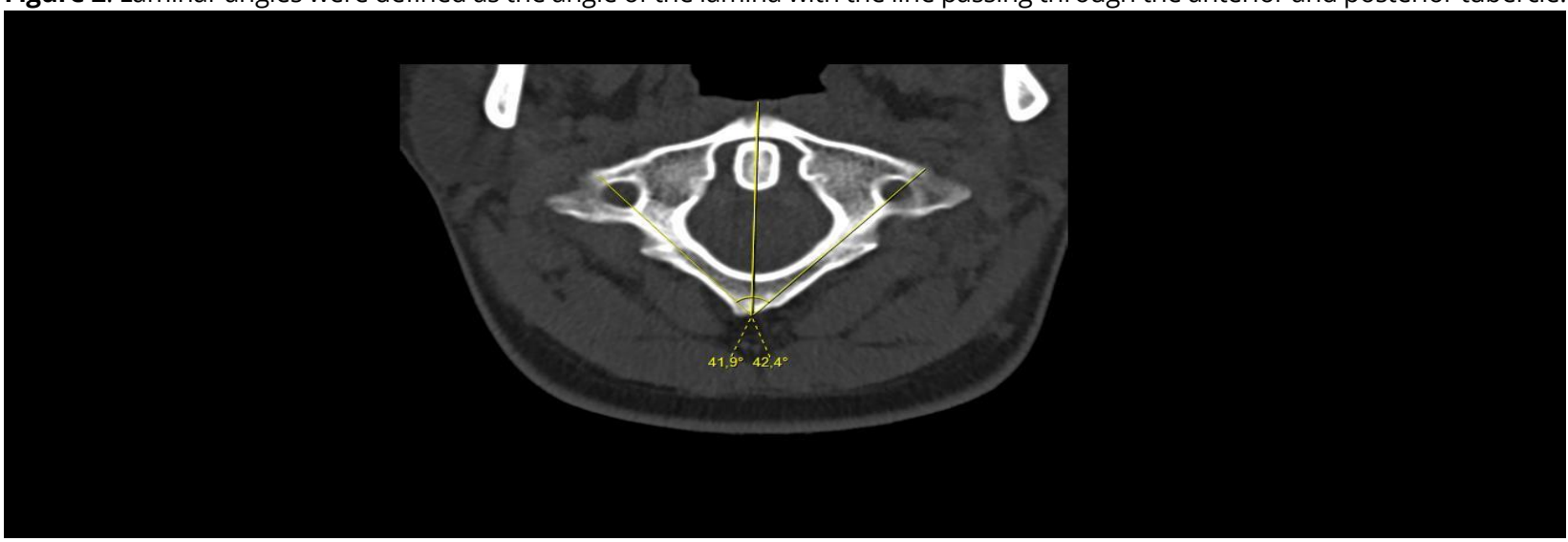




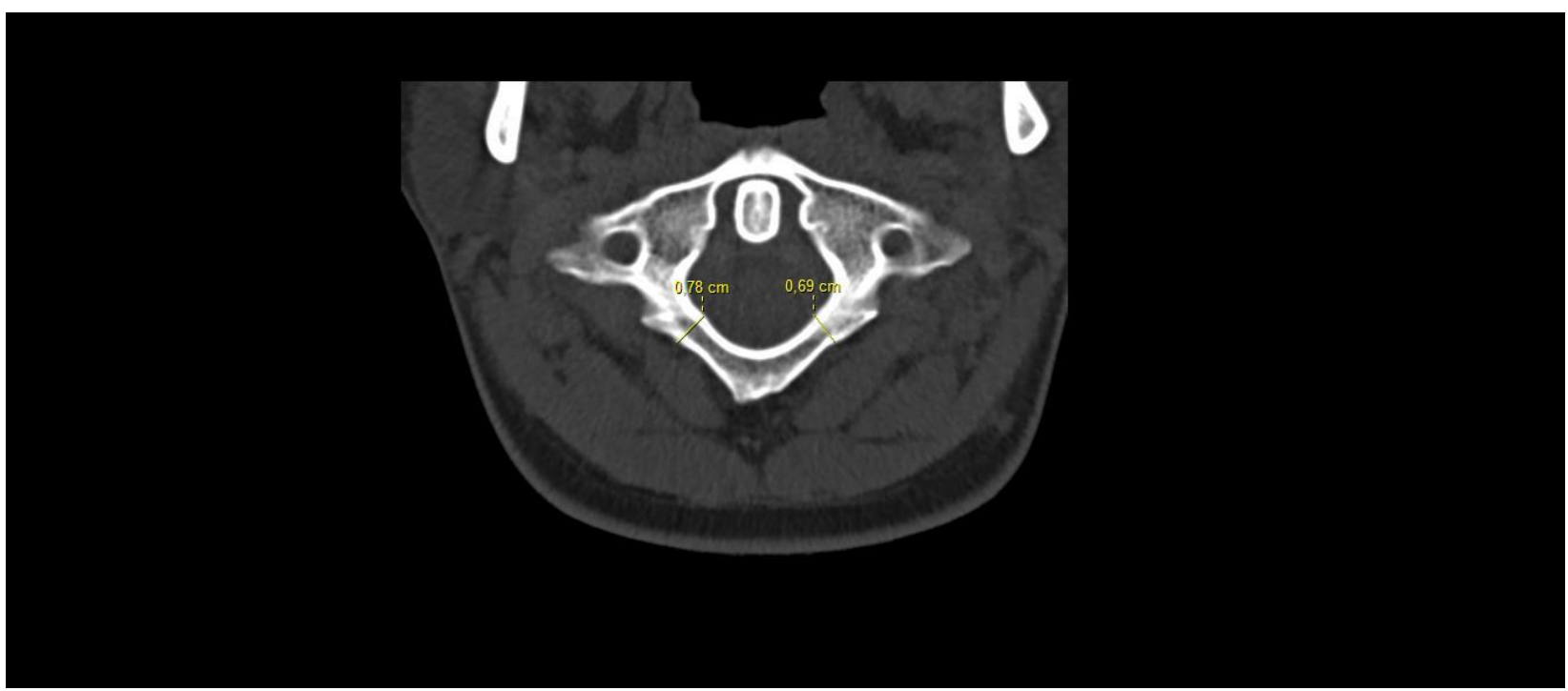

Figure 3. Axial laminar thickness was defined as the mediolateral diameter of the lamina at its middle point.

Figure 4. Coronal laminar thickness was defined superior-inferior diameter of the lamina.

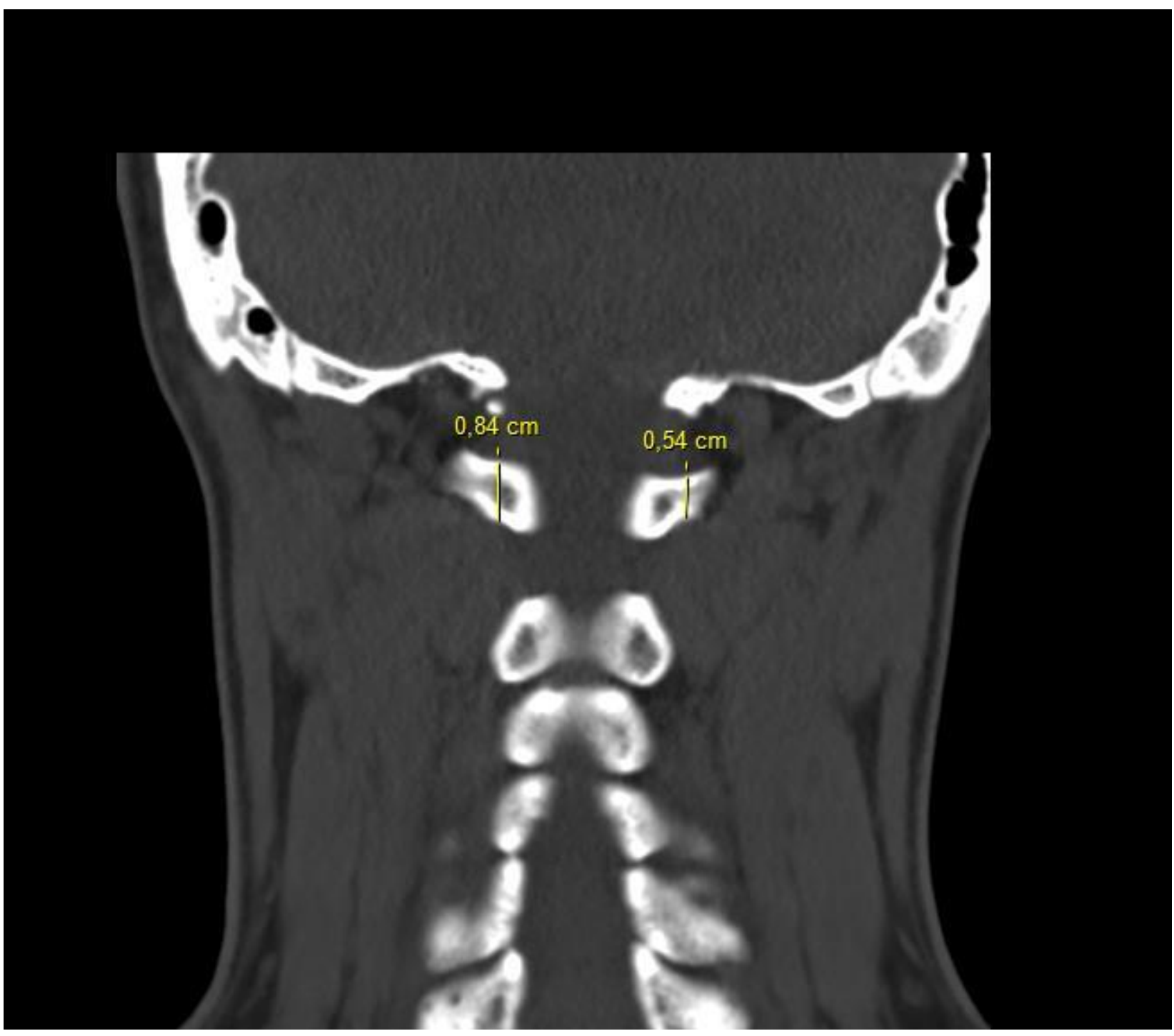




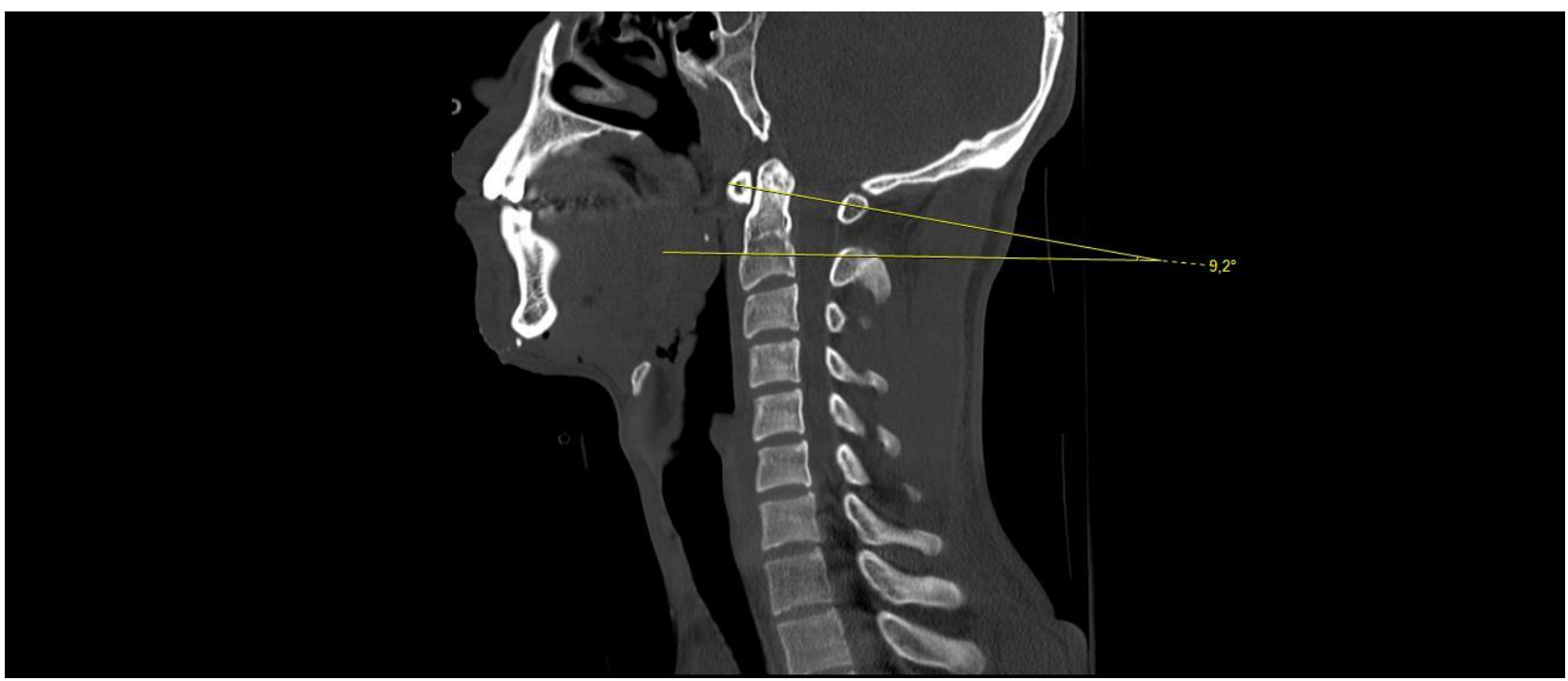

Figure 5. Cranio-caudal angle (CCA) was measured as the angle of the lamina with the line that parallel to the earth.

\section{RESULTS}

A total of 40 patients and their lamina were analyzed. Measurements belong to men and women are presented in Table 1. There were 20 men and 20 women in the study. The mean LLL was $350,8500 \pm 26,12374 \mathrm{~mm}$ in male and $315,0000 \pm 26,24380 \mathrm{~mm}$ in female. There was a statistical difference between male and female by $\operatorname{LLL}(p=.000)$. The average laminar length in right side $(\mathrm{RLL})$ in men was significantly longer $(342,0500 \pm 22,48854 \mathrm{~mm})$ than that in women $(314,5000 \pm 24,15411 \mathrm{~mm}) \quad(p=0.001)$. RLA was statistically wider in women $(48,2650 \pm 3,49666 \mathrm{~mm})$ than men $(40,5650 \pm 15,85308 \mathrm{~mm})$. LLA was measured $45,1800 \pm 10,04084 \mathrm{~mm}$ in men and $48,3200 \pm 2,94379 \mathrm{~mm}$ in women. These results revealed that no statistical significance was detected in the LLA along with men and women ( $p>0.050)$. LLAT was measured $60,9000 \pm 9,74355 \mathrm{~mm}$ in men and $61,1000 \pm 10,70121 \mathrm{~mm}$ in women. There were no statistical differences between the groups. RLAT was measured $63,6000 \pm 10,89858 \mathrm{~mm}$ in men and $61,2500 \pm 11,77363 \mathrm{~mm}$ in women. There were no statistical differences between the groups. RLCT were statistically longer in men $(57,1000 \pm 11,87611$ $\mathrm{mm})$ than women $(44,9500 \pm 12,06768 \mathrm{~mm})$. LLCT was measured $55,5500 \pm 10,56048 \mathrm{~mm}$ in men and $46,0000 \pm 12,13520 \mathrm{~mm}$ in women. There were no statistical differences between the groups. The mean CCA was $10,0250 \pm 5,07459 \mathrm{~mm}$ in male and $10,3700 \pm 5,19535 \mathrm{~mm}$ in female. There were no statistical differences between the groups.There were 25 patients (62.5\%) under 50 years and 15 patients (37.5\%) upper 50 years. Measurements belong to age are presented in Table 2. There was no statistical difference in any measurements by age.

\section{DISCUSSION}

Craniovertebral junction (CVJ) is osteoligamentous membranous complex composed between brain and spinal cord. Layers of muscles, ligaments, and membranes promote bony complex of occiput, atlas, and axis from all around which helps in providing motion as well as stability to this field. CVJ can be affected by congenital, developmental, degenerative, traumatic, and neoplastic pathologies ${ }^{9,10}$. It is very hard to diagnose instability of the CVJ and treat due to their complex anatomical composition and biomechanical characteristics. CVJ injuries may lead to sudden fatality or delayed impairment of neurological function ${ }^{11}$. Especially C1-2 fixation techniques have been improved to overcome those troubles. C1 lateral mass - C2 pedicle screw fixation using has been raised since it was presented in 1994 by Goel and Laheri ${ }^{5}$ and modified in 2001 by Harms and Melcher ${ }^{6}$. The patients that have anomalies on the bone or VA anatomy are under injury risk while performing these techniques. The authors reported C1 posterior arch screw to reduce the risk of VA injury ${ }^{12}$. The coexistence of a small pedicle and high riding vertebral artery is a risk factor for vertebral artery injury ${ }^{13}$. Interlaminar screw placement is safe in patient that have unilateral vertebral artery occlusion, patients have large paravertebral venous 
plexus, patients with fracture near lateral mass or pedicle screw placement site ${ }^{14,15}$. Studying near the fracture site can cause much bleeding. While interlaminar screw placement, surgeons don't study around large venous plexus. This situation provides to avoid much bleeding. Zarro et al compared the pullout strength of $\mathrm{C} 1$ lateral mass screw with unicortical C1 posterior arc screw. They found that unicortical C1 posterior arc screw is stronger than the $\mathrm{C} 1$ lateral mass screw in the axial direction ${ }^{16}$. Jin et al. showed that there is no statistical difference between unilateral C1 posterior arc screw- C2 laminar screw combined with unilateral C1-2 pedicular screw and whole pedicular screw insertion as performing acute stability in cadaver study ${ }^{17}$. As a result, the C1 interlaminar screw placement is safe salvage technique for craniovertebral junction stabilization and provides strong fusion.

\section{CONCLUSION}

The appropriate laminar screw sizes in the left side in men are $350 \mathrm{~mm}$ length, $60 \mathrm{~mm}$ axial thickness and $55 \mathrm{~mm}$ coronal thickness. The appropriate laminar screw trajectories in the left side in men angles were $45^{\prime}$ medio-lateral angle and $10^{\prime}$ craniocaudal angle. The appropriate laminar screw sizes in right side in men are $342 \mathrm{~mm}$ length, $40 \mathrm{~mm}$ axial thicknes and $57 \mathrm{~mm}$ coronal thickness. The appropriate laminar screw trajectories in the right side in men angles were 40' mediolateral angle and $10^{\prime}$ craniocaudal angle. The appropriate laminar screw sizes in left side in women are $315 \mathrm{~mm}$ lenght, $61 \mathrm{~mm}$ axial thickness and $46 \mathrm{~mm}$ coronal thickness. The appropriate laminar screw trajectories in the left side in men angles were $48^{\prime}$ mediolateral angle and $10^{\prime}$ craniocaudal angle. The appropriate laminar screw sizes in the right side in women are $314 \mathrm{~mm}$ length, $61 \mathrm{~mm}$ axial thickness and $44 \mathrm{~mm}$ coronal thickness. The appropriate laminar screw trajectories in the left side in men angles were $48^{\prime}$ mediolateral angle and $10^{\prime}$ craniocaudal angle.

\section{REFERENCES}

1. Arslan SG, Dildes N, Kama JD. Cephalometric investigation of first cervical vertebrae morphology and hyoid position in young adults with different sagittal skeletal patterns. Sci World J. 2014;2014:159784.
2. Gallie WE. Fractures and dislocations of the cervical spine. Am J Surg. 1936;46:495-9.

3. Brooks AL, Jenkins EB. Atlanto-axial arthrodesis by the wedge compression method. J Bone Joint Surg Am. 1978;60:279-84.

4. Grob D, Magerl F. Surgical stabilization of C1 and C2 fractures. Orthopade. 1987;16:46-54.

5. Goel A, Laheri V. Plate and screw fixation for atlantoaxial subluxation. Acta Neurochir (Wien). 1994;129: 47-53.

6. Harms J, Melcher RP. Posterior C1-C2 fusion with polyaxial screw and rod fixation. Spine (Phila Pa 1976). 2001;26:2467-71.

7. Burke JP,Gerszten PC,WelchWC. latrogenic vertebral artery injury during anterior cervical spine surgery. Spine J. 2005;5(5):508-514.

8. Smith MD, Emery SE, Dudley A, Murray KJ, Leventhal M. Vertebral artery injury during anterior decompression of the cervical spine. A retrospective review of ten patients. J Bone Joint Surg Br. 1993;75-B(3):410-415.

9. Rhoton AL., Jr The foramen magnum. Neurosurgery. 2000;47(Suppl 1):S155-93. [PubMed]

10. Kawashima M, Tanriover N, Rhoton AL, Jr, Ulm AJ, Matsushima T. Comparison of the far lateral and extreme lateral variants of the atlanto-occipital transarticular approach to anterior extradural lesions of the craniovertebral junction. Neurosurgery. 2003;53:662-74.

11. Dickman CA, Papadopoulos SM, Sonntag VK, Spetzler RF, Rekate $\mathrm{HL}$, Drabier J : Traumatic occipitoatlantal dislocations. J Spinal Disor. 1993;6 : 300-313.

12. Jin GX, Wang $\mathrm{H}$, Li L, et al. C1 posterior arch crossing screw fixation for atlantoaxial joint instability. Spine (Phila Pa 1976). 2013; 38(22): E1397-E1404.

13. Yeom JS, Buchowski JM, Kim HJ, Chang BS, Lee CK, Riew $\mathrm{KD}$. Risk of vertebral artery injury: comparison between C1-C2 transarticular and C2 pedicle screws. Spine J. 2013;13:775-785.

14. Matsubara T, Mizutani J, Fukuoka M, et al. Safe atlantoaxial fixation using a laminar screw (intralaminar screw) in a patient with unilateral occlusion of vertebral artery: case report. Spine (Phila Pa 1976). 2007; 32(1): E30-E33.

15. Ma XY, Yin $\mathrm{QS}, \mathrm{Wu} Z \mathrm{ZH}$, et al. $\mathrm{C} 1$ pedicle screws versus $\mathrm{C1}$ lateral mass screws: comparisons of pullout strengths and biomechanical stabilities. Spine (Phila Pa 1976). 2009; 34(4): 371-377.

16. Zarro CM, Ludwig SC, Hsieh $\mathrm{AH}$, et al. Biomechanical comparison of the pullout strengths of $\mathrm{C} 1$ lateral mass screws and C1 posterior arch screws. Spine J. 2013; 13(12): 1892-1896.

17. Jin $\mathrm{GX}$ and Huan W. Unilateral C-1 posterior arch screws and C-2 laminar screws combined with a 1-side C1-2 pedicle screw system as salvage fixation for atlantoaxial instability. J Neurosurg Spine. 2015; 24: 315-320. 